\title{
A importância da intervenção precoce com pais de bebês que nascem com alguma deficiência
}

\section{The importance of early intervention with parents of babies who are born with a deficiency}

\author{
Carla Anauate* \\ Maria Lúcia T. M. Amiralian**
}

\begin{abstract}
RESUMO
O presente trabalho, à luz da teoria de Winnicott, que elucida a importância do ambiente e da relação interpessoal para a constituição de um ser humano saudável, pretende apresentar uma proposta de intervenção para trabalhar com os pais de bebês que nascem com alguma deficiência. É no apontar a dois que se confirma a realidade, que se vê nos olhos do outro o seu próprio olhar. Para tanto, o primeiro cuidador, instrumentalizado com informações e orientações poderá propiciar meios para que esse bebê se desenvolva plenamente. Respeitando as suas iniciativas espontâneas e originais, seu modo de se expressar, e sendo contingente em retorno, proporcionará a essa criança um sentido de aceitação e de compreensão de suas expressões, inserindo-a adequadamente no meio circundante.

Palavras-chave: deficiência; relacionamento; desenvolvimento da criança; contingência.
\end{abstract}

* Mestranda em Psicologia Escolar e do Desenvolvimento Humano pela Universidade de São Paulo (USP). Professora do Instituto de Psicologia Aplicada e Formação (Ipaf). Psicóloga Escolar - trabalho com deficientes auditivos em EMEFS do Município de Osasco, SP. E-mail: carla@ramark.com.br

** Doutora em Psicologia Clínica pela Universidade de São Paulo (USP). Professora no Instituto de Psicologia da Universidade de São Paulo, no Programa de Pós-Graduação em Psicologia Escolar e do Desenvolvimento Humano. Coordenadora do Laboratório Interunidades para o Estudo das Deficiências (Lide), na Universidade de São Paulo. E-mail: mltma@usp.br 
ANAUATE, C.; AMIRALIAN, M. L. T. M. A importância da intervenção precoce com pais de bebês que nascem com alguma deficiência

\begin{abstract}
The present article, using Winnicott's theory as a background, which elucidates the importance of the environment and of social relations to constitute a healthy human being, intends to present an intervention proposal with parents of a newborn deficient baby. It is by pointing at reality two by two that one sees in the eyes of the other his own eyes. In spite of this, the first caregiver, instructed with information and orientations, will be able to offer conditions for this deficient baby to develop himself completely. It is by respecting the spontaneous and original initiatives of the baby, his own way of expressing himself, and by being contingent in return, that this child will be able to acknowledge a sense of acceptance and comprehension of his own expressions, positioning him adequately into the environment.

Key-words: deficiency; relationship; child development; contingency.
\end{abstract}

\title{
Introdução
}

Apresentamos-nos envolvidas com a questão do desenvolvimento afetivo de pessoas com deficiências e de suas interações na sociedade. Acreditamos, portanto, ser de suma importância a intervenção precoce proporcionada a pais de crianças que nascem com alguma deficiência. Informações, respostas, repartir e compartilhar o luto, são questões fundamentais a serem trabalhadas nesse processo de chegada de um bebê com deficiência em uma família.

Deficiência é a perda ou anormalidade de estrutura ou função psicológica, fisiológica ou anatômica, temporária ou permanente. Incluem-se nessas a ocorrência de uma anomalia, defeito ou perda de um membro, órgão, tecido ou qualquer outra estrutura do corpo, inclusive das funções mentais. Representa a exteriorização de um estado patológico, refletindo um distúrbio orgânico, uma perturbação no órgão (AMIRALIAN et al., 2000, p. 98). 
A partir dessa definição, acreditamos como primordial poder disponibilizar recursos para que os pais desses bebês possam ser orientados precocemente na forma como se relacionar de maneira satisfatória com seu filho com deficiência. Dessa forma, orientados, terão condições de proporcionar a essas crianças um contato adequado, eficaz e autêntico com o meio que os circunda, permitindo, assim, que venham a desenvolver um sentido real de eu, do outro e da realidade.

A teoria de Winnicott embasa este trabalho no sentido de priorizar a interação de dois seres humanos, dos quais um é capaz de suprir as necessidades do outro, exercendo, dessa forma, a função materna. Da mesma maneira, Bock (2002) e Vygotsky (1994) enfatizam que é somente dentro de relações sociais que o homem vai se constituindo. Consideramos, portanto, que o ser humano precisa da referenciação mútua para poder perceber que o outro também percebe o mundo da mesma maneira que ele. Amiralian (2003) menciona que para Winnicott o ser humano constitui-se na interação com o ambiente por meio das suas vivências. Enfatizamos que, ao compartilhar os seus aspectos vivenciais, estes se tornam palpáveis, fazendo sentido, incorporando, dessa forma, todo um imaginário simbólico.

Consideramos importante a utilização da estimulação precoce nomeada por Jerusalinsky e Coriat (1983), que ressalta que a função materna exercida a contento proporciona inconscientemente um espaço para que os intercâmbios decisivos entre a mãe e seu filho ocorram de maneira espontânea. Com esse trabalho, os pais dessas crianças terão a possibilidade de compreender, aceitar e elaborar melhor esse universo tão desconhecido e diferente, para, assim, proporcionar aos seus filhos com deficiência um desenvolvimento adequado.

Para tanto, entendemos que a intervenção precoce com os pais abre um caminho para um maior ajustamento social desses bebês. Possibilitar ao bebê com deficiência um contato adequado com a realidade, para que seja inserido e aceito como um ser humano, com as suas limitações específicas, é o intuito deste artigo. Por meio de metábolos (Leal, 2003), ou seja, formas de agir utilizadas em experiências partilhadas, uma adaptação adequada será viabilizada.

Metábolos são apresentados no contexto de experiências partilhadas com parceiros mutuamente envolvidos que funcionam como mediadores da diferenciação eu/coisas/outros e, por esta via, introduzem a competência para simbolizar, ou seja, para separar ou abstrair significados das coisas/eventos dentro da relação. Em conseqüência, tornam-se possíveis intercâmbios mais flexíveis e abre-se caminho para a assimilação cognitiva (LeAL, 2003, p. 52). 
ANAUATE, C.; AMIRALIAN, M. L. T. M. A importância da intervenção precoce com pais de bebês que nascem com alguma deficiência

\section{Referencial teórico}

Percebemos ser essencial para um bebê ter o contato do olhar para que se estabeleça uma interação e uma integração desse ser humano com o ambiente. Andersen (1996) confirma essa questão quando coloca que o olhar é de importância fundamental no início de uma interação entre duas pessoas. Portanto, enfatizamos que o cuidador deve sempre manter esse contato vivo e autêntico, beneficiando a adaptação desse bebê ao mundo. A esse exemplo, Winnicott (1975) questiona: "O que vê o bebê quando olha para o rosto da mãe?” Menciona que o que o bebê vê é ele mesmo. Em outras palavras, a mãe está olhando para o bebê e aquilo com o que ela se parece se acha relacionado com o que ela vê em seu filho.

Consideramos, como confirmam Bevilacqua e Formigoni (2000), que o incentivo à comunicação, por meio da interação, deve ser proporcionado desde cedo. Afirmamos que, desde o nascimento, mãe e bebê devem interagir. Ao olhar o bebê, a mãe conversa com ele, estimulando a comunicação e dando a esta a devida importância. Contudo, quando a mãe percebe que o seu bebê é portador de deficiência, muitas vezes fica desestimulada e corta o canal de interação. Pensamos que, a partir dessa constatação, pode-se instalar nas mães um estado depressivo.

A descoberta de uma deficiência no filho, com todas as perdas que envolve, é uma situação propiciadora ao desenvolvimento de um estado depressivo na mãe, que a levará ao afastamento de seu bebê, impedindo-a de alcançar o estado de preocupação materna primária, necessário a uma boa acolhida deste. E nesse momento inicial, quando o bebê necessita que lhe seja fornecida uma total adaptação a suas necessidades, ele, muitas vezes, é posto em um lugar de estranheza e desconhecimento, com a mãe sofrendo suas próprias dores, que a tornam incapacitada para assumir seu papel (Amiralian, 2003, p. 106).

Consideramos que, ao nascer um filho com deficiência numa família, há um contraste muito grande entre o filho esperado e o que acaba de nascer, afetando a função materna, pois a mãe sofre pelo luto da perda do filho imaginado, sentindo o bebê deficiente como um impostor. Faz-se importante salientar que a espera de um filho está invariavelmente pautada em expectativas 
a serem confirmadas no nascimento. Portanto, acreditamos que o trabalho a ser desenvolvido deve visar a uma melhor elaboração desse luto em prol de um contato mais satisfatório entre mãe e bebê.

A sustentação, a manipulação, a tarefa de conectar a criança com o meio, a transmissão da linguagem, o jogo, tudo pode e costuma ficar profundamente perturbado quando o déficit constitucional do bebê produz um desencontro precoce entre a mãe e seu filho. A estimulação precoce encontra uma brecha neste desencontro e no desejo parental de solucioná-lo. É necessário, então, reconstruir os aspectos prejudicados da função materna, às vezes até substituí-la parcial ou totalmente, enquanto dura a crise da mãe, sendo que muitas vezes é possível proporcionar-lhe elementos de sustentação durante sua luta para recompor sua posição de mulher disposta a criar um filho. É preciso sublinhar que a fragilidade desta criança não admite muitos atrasos, já que as conseqüências de um distanciamento materno podem ser graves e, se prolongadas por meses, irreversíveis. Assim, podem instalar-se traços autistas, pode-se perder a oportunidade de moderar expressões patológicas do sistema nervoso e neuromuscular (JERUSALINSKY; CORIAT, 1983, p. 80).

Acreditamos que a referenciação mútua entre mãe e filho, no confronto com os fatos e acontecimentos, proporciona uma via aberta para a aprendizagem. Portanto, a falha desse modelo triádico de estruturação de significados impossibilita a construção do pensamento. A partir do momento em que a mãe se sente desestimulada a comunicar-se com o seu bebê deficiente, perde-se a referenciação mútua e tudo o que esta proporciona. Aprender, portanto, diz respeito a estruturar significados internamente que só podem ser adquiridos dentro de um relacionamento contínuo, um terceiro que se estabelece como figura adulta confirmadora, que troca coisas com pessoas, em ida-e-volta.

Este relacionamento resulta da iniciativa da criança de procurar a resposta das coisas aos seus actos. Define-se como sistema de significados criados num registro de ressonância emocional. Propõe-se que, deste modo, se estabeleça uma relação em que se descobrem significados que são novos, que não pertencem ao mundo das percepções nem ao campo das fantasias internas e privadas, mas se movem numa área transitiva, intermédia, da experiência - a área do símbolo e do ludo (LeAL, 1985, p. 72). 
ANAUATE, C.; AMIRALIAN, M. L. T. M. A importância da intervenção precoce com pais de bebês que nascem com alguma deficiência

Afirmamos que é por meio da atividade externa que se criam as possibilidades de construção da atividade interna. Assim, progressivamente, pela mediação, pelas relações sociais, o homem vai se constituindo. Bock (2002) e Ozella (2003) enfatizam que o psiquismo se constitui na relação que o homem trava com o mundo sociocultural, afirmando que o homem se constrói ao construir a sua realidade. Daí a importância que consideramos de um meio acolhedor para que o ser humano possa estabelecer relações contingentes a partir das quais ele vai se firmar como autônomo, capaz de construir sentidos subjetivos. O ambiente externo só tem sentido quando é significado pela subjetividade de cada um. Faz-se necessário, portanto, constituir um mundo interno que possa essar em contínua troca de significados e sentidos com o mundo externo, para que essa relação seja mutuamente compartilhada. Winnicott (1990) reitera essa questão quando menciona que a família representa o ambiente inicial e fundamental para que o indivíduo possa vir a ser. Loparic (1996), por sua vez, cita que falhas nesse ambiente inicial, no relacionamento mãe-ambiente, ocorrem por este não ser confiável e suficiente para assegurar o crescimento e a evolução pessoal do ser humano. Acreditamos que o bebê necessita da presença segura da mãe, que lhe inspire a fé em si mesmo e no mundo. $\mathrm{O}$ bebê só tem a possibilidade de usar os seus mecanismos mentais se o contato com a mãe-ambiente for suficientemente bom.

Se o ambiente não proporcionar essa confiança, o bebê passa a senti-lo como ameaçador, e angústias impensáveis começam a ser experimentadas por ele. Consideramos que essas angústias são muito precoces e ameaçam o existir humano, ocorrem antes do ser humano ter a possibilidade de iniciar as atividades relativas a mecanismos mentais e a forças instintuais. O objetivo deste trabalho é poder conscientizar os pais de crianças com deficiência dessas questões, para que eles tenham informações suficientes do que pode ocorrer quando eles se relacionarem com essa criança.

É vitalmente importante que, ao cuidar de seus bebês, as mães, no início fisicamente, e logo também imaginativamente, comecem fornecendo esta adaptação ativa, mas também é uma característica da função materna fornecer um fracasso gradual da adaptação, de acordo com a habilidade crescente que cada bebê tem de compensar o fracasso relativo através da atividade mental ou da compreensão. Desta forma, aparece no bebê uma tolerância com relação tanto à necessidade do ego quanto à tensão pulsional (WINNICOTT, 1949, p. 413). 
Notamos que as crianças têm uma importante necessidade de autoconsciência e autoconfiança, que são qualidades a serem desenvolvidas no contato com modelos adultos, que as aceite como seres humanos capazes, respeitando as suas condições inerentes. Dentro dessa perspectiva, essas crianças precisam somente de cuidados especiais que lhes forneçam os recursos necessários de acordo com a limitação causada pela sua deficiência. À parte disso, são simplesmente crianças. A formação da identidade dessas crianças só se dará por meio da interação com os outros. Essa identidade será adquirida de acordo com a atitude do ambiente perante elas, uma atitude de respeito. $\mathrm{O}$ intuito final é que essas crianças se tornem responsáveis e que tenham condições de explorar suas habilidades e potencialidades, cuidar de si mesmas e interagir positivamente com outras pessoas.

\section{A intervenção precoce}

Achamos importante, neste momento, mencionar alguns ensinamentos de D. W. Winnicott que traçam os pontos principais que norteiam a intervenção precoce.

A sustentação (holding) como meio de segurança afetiva, a manipulação (handling) diferenciada como modo de libidinizar seletivamente o corpo do bebê, apresentação dos objetos do meio (to show the world) como forma de dirigir a criança ao mundo externo e descentrá-la da relação exclusiva com sua mãe (Coriat; Jerusalinsky, 1983, p. 81).

Acreditamos que todas estas são funções maternas e que fornecem condições indispensáveis para que o bebê possa sentir-se como um todo, habitando um corpo apto a relacionar-se com o ambiente externo. Para tanto, a mãe deve ser suficientemente boa, na medida certa para atender, no tempo e de maneira adequada, às necessidades do bebê.

Os pais que adotam uma atitude de superproteção para com seus filhos, fazendo tudo por eles, inclusive aquelas atividades que eles poderiam 
ANAUATE, C.; AMIRALIAN, M. L. T. M. A importância da intervenção precoce com pais de bebês que nascem com alguma deficiência

facilmente realizar, além de estarem impedindo importantes experiências favorecedoras de seu desenvolvimento, estão, também, lhes transmitindo um conceito de incapacidade e insuficiência de difícil superação. Estas crianças tendem a desenvolver excessiva dependência por toda sua vida. Já os pais que tem dificuldades em aceitar as limitações impostas pela deficiência colocam uma excessiva pressão sobre a criança para que ela se desenvolva e funcione normalmente. Esta condição, além da alta carga ansiógena que produz, pode levar a criança a atitudes de extrema agressividade, tentativa de manipulação de seus pares, e extrema dependência ao objeto externo, numa tentativa de satisfação do desejo dos pais. Estas crianças podem desenvolver um falso self, não conseguindo atingir um desenvolvimento pleno e satisfatório (AMIRALIAN, 2003b, p. 109).

Consideramos fundamental que os pais sejam instruídos a permitir que a criança seja ela mesma, autêntica, com as suas iniciativas respeitadas. A intrusão, ou seja, a tentativa do cuidador de impor o seu eu à criança, deve ser evitada para que não se crie um falso self. Afinal, o nosso intuito com este artigo é propiciar condições para que se crie um ser humano original, espontâneo e único.

Acreditamos, como confirma Winnicott (1993), que deve haver um meio ambiente suficientemente bom, que permita ao bebê alcançar, em cada estádio, as satisfações, ansiedades e conflitos inatos apropriados. Esse ambiente compreende a preocupação materna primária, que corresponde a um estado de sensibilidade aumentada, no qual a mãe volta-se inteiramente para o seu bebê. Para viver esse momento, pensamos que a mãe necessita ter um desenvolvimento sadio e um ambiente protetor que a sustente. Esse ambiente é o que ambicionamos proporcionar a esses cuidadores no momento em que descobrem que seu bebê tem uma deficiência.

Percebemos, como confirmam Foster e Jerusalinsky (1993), que é por meio da mãe que são introduzidos, no campo das relações com o seu filho, elementos que darão apoio a esse filho com deficiência. Portanto, achamos, como Paez (1993), que um orientador deverá mostrar todas as possibilidades da criança, marcando a sua realidade de pessoa em crescimento com as suas limitações. Os orientadores devem saber aceitar as dificuldades como desafios, sabendo que nem todos serão vencidos, e tomar todas as conquistas como base para favorecer o desenvolvimento das estruturas superiores. Nesse trajeto, passarão por diversos momentos. Entre eles, a esperança de vencer todos os obstáculos e a impotência que paralisa diante da realidade dessa criança com condições limitantes. Cada carícia, cada movimento, cada busca do olhar desse 
bebê, são contatos, encontros e reencontros que devem ser valorizados. Essas ações devem ser pensadas como estímulos que provocarão respostas, animando o cuidador a buscar novas formas de contato. Dessa maneira, um circuito de retroalimentação afetiva e cognitiva se instalará. Cada resposta provocará um novo estímulo, que gerará uma nova resposta, ampliando uma rede de reação circular de atenção. O que começou como uma indicação de contato passa a ser um pedido que mostra o desejo da mãe de fazer e dar sentido, cada vez mais, a esse filho. Acreditamos que o primordial é disponibilizar recursos para que essa mãe dê sentido e, conseqüentemente, que essa criança faça sentido como filho para essa mãe.

Podemos dizer, como Leal (2003), que ter o eu organizado é um prérequisito básico para que ocorra qualquer aprendizagem, e essa organização do $e u$ se estabelece numa função dialógica primária, ou seja, nos intercâmbios socioemocionais que ocorrem de forma recíproca e alternante e de maneira mutuamente contingente, e assim o bebê se percebe originando os próprios atos e expressões. Consideramos que, ao utilizar um padrão fundamental de alerta sensorial, em que se encontra o intercâmbio de vai-e-vem entre humanos, proporcionaremos a formulação de significados partilhados.

A comunicação em ida-e-volta, desde os primórdios, pode ser observada na vida do bebê pela atenção que este volta para os ritmos de contingências mútuas, ritmos que surgem nos intercâmbios entre coisas e pessoas, seguidos por expressões de prazer.

A teoria de Leal (2003) serviu de base para configurar um modelo de intervenção psicológica em que se inventam mediadores, ou seja, instrumentos que viabilizam a relação entre coisas e pessoas, em ida-e-volta, de modo a integrar coisas e pessoas, proporcionando a construção de significados.

A introdução de mediadores, instrumentos ou modos de se relacionar que integram pessoas e coisas, com as características específicas mencionadas, desencadeia novos modos de comunicação. Podemos afirmar que a construção dos mediadores, ou seja, as interações que funcionam em vai-e-vem, são definidas como organizadoras pré-simbólicas da relação entre pessoas. Acontecem em situações de entrevista não-diretiva em que, ao manusear objetos, ou relatos, estabelecem intercâmbios sucessivos e alternantes entre pessoas e coisas, respeitando, sempre, as iniciativas do bebê às quais há uma contingência.

Propomos que um processo individual de encontro e/ou construção de significados pessoais possa ser promovido por meio de atos realizados entre duas pessoas que sejam apontadas e/ou nomeadas por ambos como respeitando a algo externo aos dois, mas partilhado por ambos. 
ANAUATE, C.; AMIRALIAN, M. L. T. M. A importância da intervenção precoce com pais de bebês que nascem com alguma deficiência

Dessa forma, os intercâmbios expressivos entre pessoas, quando dentro de contextos que dêem lugar ou permitam o aparecimento de seqüências e ritmos na interação entre os interlocutores presentes, originariam a percepção de contingência de respostas, ou seja, o ambiente estaria sendo contingente aos próprios atos.

A utilização desse modelo será de fundamental importância para os bebês que nascem com deficiências. Ao abrir caminho para a interação social e a referenciação mútua, o deficiente terá condições de uma percepção diferenciada, mais assertiva, com mais significado. Dessa forma, terá mais possibilidades de desenvolvimento cognitivo e emocional e, conseqüentemente, maior inserção social. Percebemos que vários fatores influenciam esses casos.

A influência da deficiência está relacionada a inúmeros fatores: o tipo de deficiência, sua intensidade, sua extensão, época de sua incidência e, principalmente, as oportunidades de desenvolvimento e ajustamento que foram oferecidas ou negadas às pessoas dela portadora (AmIRALIAN, 1997, p. 33).

Aspectos importantes devem ser considerados em processo de intervenção aos pais: diagnosticar o mais precocemente possível a deficiência, de preferência ainda na maternidade, é uma condição fundamental para proporcionar à família desse bebê com deficiência, recém-nascido, condições de uma intervenção. Acreditamos que trabalhar, no próprio hospital, desde o momento da notícia até um acompanhamento, pós-alta, poderá proporcionar a esses pais condições de estabelecer uma relação mais favorecedora ao desenvolvimento do seu bebê.

Dois fatores são essenciais para a constituição e desenvolvimento do ser humano: a tendência inata do indivíduo para a integração e para o amadurecimento e a existência de um ambiente facilitador. Deste princípio pode-se inferir uma constante: qualquer que seja o potencial herdado, ele só se realizará pelos cuidados de um outro ser humano, preferencialmente a mãe. E, pode-se acrescentar, um desenvolvimento saudável significando a realização plena de si mesmo, de suas possibilidades (AMIRALIAN, 2003c, p. 104). 
Percebemos o momento da notícia como parte integrante da intervenção. É uma hora delicada, sensível, na qual se estabelece o luto, e este deve ser respeitado e acolhido como tal, sem minimizá-lo. A notícia deverá ser dada e posteriormente acompanhada por uma equipe interdisciplinar de psicólogos e profissionais da área da deficiência e o médico. Esses profissionais precisarão estar à disposição da família para esclarecer todas as suas inúmeras dúvidas, questões e, principalmente, para sustentar suas angústias. Um casal que tem filho com a mesma deficiência do bebê recém-nascido deverá ser chamado para, assim que os pais recém-noticiados estiverem em condições, poder compartilhar experiências, acalentando e alertando sobre especificidades práticas e emocionais da deficiência em questão. Em seguida, atendimentos individuais e atividades grupais serão propostos. Atendimentos individuais no intuito de disponibilizar espaço para que esses pais possam falar sobre questões difíceis de ser compartilhadas, angústias, frustrações, enfim, espaço para a elaboração de um luto. Atividades grupais em que pais veteranos poderão compartilhar experiências, lutos, conquistas e diferenças com os recém-pais, em caráter de grupo de apoio. Acreditamos que alguns pontos básicos devem ser cuidados no trabalho de orientação a pais. Amiralian (2003) salienta esses pontos fundamentais: discutir o significado da deficiência com os pais e com toda a família, assinalando o significado de ter um filho deficiente e o significado da deficiência em si; diminuir a ansiedade dos pais, levando-os a perceber suas competências para criar um filho, mesmo que este tenha uma deficiência; diminuir a autocrítica dos pais em relação a atitudes para com os filhos e, finalmente, proporcionar condições para que os pais possam assumir de forma tranqüila e prazerosa suas responsabilidades de educação e escolarização desse seu filho com deficiência. O intuito, portanto, resume-se à proposta de orientar e informar essas famílias sobre tudo o que concerne a receber e aceitar um novo membro, deficiente, na família, proporcionando, assim, uma melhor adaptação desse deficiente na comunidade de maneira geral.

As atividades propostas deverão ter como objetivo principal a relação, a referenciação mútua, o apontar a dois. Atividades serão adaptadas de forma a se tornar metabolizadoras de apreensão de significados. Rodas de conversa serão disponibilizadas para trocar, em ir-e-vir, experiências comuns ou adversas, que construam conceitos comuns. Essas rodas deverão ocorrer sempre esperando a iniciativa de um participante para, em retorno, lhe ser contingente. Nessas ocasiões, surgindo a necessidade de se trabalhar um conceito, os pais deverão ser colocados em grupos para chegar a uma definição comum desse conceito. Acreditamos que esse momento do compartilhar, do apontar a dois, de criar significados, seja primordial para o futuro emocional desses bebês com deficiência. 


\section{Considerações finais}

Consideramos que o mais importante é proporcionar espaço para acontecer a interação, criando-se um mundo comum, identificado também pelo outro como existente, confirmando, assim, a realidade. Amiralian (2003) confirma essa colocação, afirmando que constituir um ser como indivíduo total, integrado, habitando um corpo tendo capacidade de se relacionar com outros seres humanos respaldado por um ego fortalecido, é o objetivo fundamental dessa intervenção precoce com os pais, que serão instruídos a propiciar essas condições, permitindo, assim, a entrada dessas crianças no mundo e na sociedade.

Finalizamos este artigo mencionando uma afirmação de Winnicott que sintetiza a nossa crença. Winnicott (1975) coloca que o desenvolvimento é um processo que evolui da dependência absoluta para a independência a partir das interações primitivas do bebê com o ambiente, em primeira instância com a mãe. As interações mãe-bebê são o ponto básico a partir do qual se organizarão as relações com o mundo, elemento principal na constituição do sujeito como sujeito psíquico. Nessa interação adequada, com pais devidamente orientados e fortalecidos, a criança com deficiência terá elementos e condições de um desenvolvimento absolutamente condigno, considerando as suas limitações, estabelecendo-se como um ser integrado e com noções claras e reais do eu, do outro e da realidade.

\section{REFERÊNCIAS}

AMIRALIAN, M. L. T. M. A clínica do amadurecimento e o atendimento às pessoas com deficiência. Natureza Humana, v. 5, n. 1, jan.-jun. 2003a.

. A deficiência redescoberta: a orientação de pais de crianças com deficiência visual. Revista Psicopedagogia, v. 20, n. 62, p. 107-115, 2003.

. Deficiências: um novo olhar. Contribuições a partir da psicanálise winnicottiana.

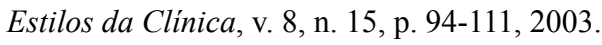

AMIRALIAN, M. L. T. M. et al. Conceituando deficiência. Revista Saúde Pública, São Paulo, v. 34, n. 1, p. 97-103, 2000. 
ANDERSEN, F. Do silêncio de Deus à mãe medusada. Lisboa: Colibri, 1996.

BECKER, E. et al. Deficiência: alternativas de intervenção. In: PINTO, E. B. Ludoterapia com crianças que apresentam deficiência intelectual. São Paulo: Casa do Psicólogo, 1997. Cap. 2.

BEVILACQUA, M. C.; FORMIGONI, G. M. P. Audiologia educacional: uma opção terapêutica para a criança deficiente auditiva. Carapicuiba: Pró-Fono Departamento de Editorial, 2000.

BOCK, A. M. B. A perspectiva sócio-histórica na formação em psicologia. Rio de Janeiro: Vozes, 2003.

BOCK, A. M. B.; GONÇALVES, M. G. M.; FURTADO, O. Psicologia sócio-histórica (uma perspectiva crítica em psicologia). São Paulo: Cortez, 2002.

CORIAT, L. F.; JERUSALINSKY, A. N. Definição de estimulação precoce. Escritos da Criança, Porto Alegre, n. 1, 1993.

FOSTER, O. H.; JERUSALINSKY, A. N. Bases neuropsicológicas de la estimulación temprana. Cuadernos del Desarollo Infantil, Buenos Aires, v. 2, 1993.

LEAL, M. R. M. Comunicação primária e intercâmbio mutuamente contingente. São Paulo: Terceira Margem, 2003.

. Introdução ao estudo dos processos de socialização precoce da criança. Lisboa: Edição da Autora, 1985.

LOPARIC, Z. Winnicott: uma psicanálise não-edipiana. Percurso, n. 17, p. 41-47, 1996.

OZELLA, S. Adolescências construídas. São Paulo: Cortez, 2003.

PAEZ, S. C. La estimulación temprana como sosten de la función materna. Escritos da Criança, Porto Alegre, n. 1, 1997.

VYGOTSKY, L. S. A formação social da mente. São Paulo: Martins Fontes, 1994.

WINNICOTT, D. W. (1949) A mente e sua relação com psique-soma. In: . Textos selecionados: da pediatria à psicanálise. Rio de Janeiro: Francisco Alves, 1993.

. O papel do espelho da mãe e da família no desenvolvimento infantil. In:

O brincar e a realidade. Rio de Janeiro: Imago, 1975. 
ANAUATE, C.; AMIRALIAN, M. L. T. M. A importância da intervenção precoce com pais de bebês que nascem com alguma deficiência

. Natureza humana. Rio de Janeiro: Imago, 1990.

. (1955) Variedades clínicas da transferência. In:

Textos selecionados: da

pediatria à psicanálise. Rio de Janeiro: Francisco Alves, 1993.

Texto recebido em 21 abr. 2006

Texto aprovado em 13 out. 2006 